\title{
4. Comparing long-term scarring effects of unemployment across countries: the impact of graduating during an economic downturn ${ }^{1}$
}

\section{Laura Alexandra Helbling, Stefan Sacchi and Christian Imdorf}

\section{INTRODUCTION}

Youth employment prospects are highly sensitive to the business cycle, and especially so at labour market entry. Young workers tend to be the last in and therefore the first out when an economy declines (Vandenberghe, 2010: 4-5). In the Great Recession beginning in 2008, youth unemployment peaked at record-high levels, followed by only slow improvement (OECD, 2017). A number of observers have been concerned that young people who were left without work or engaged in insecure employment during the recession may become a lost generation (OECD Observer, 2010). These youth cohorts may not only find it difficult to establish themselves in the labour market in the short term but may also experience lasting negative consequences for their careers (Arulampalam et al., 2001). The exposure to unemployment adversely impacts on young people's subsequent careers and labour market integration, as well as on their future subjective well-being.

It is not possible to fully explain these long-term consequences through individual characteristics such as low qualifications, low motivation or a lack of abilities (Biewen and Steffes, 2010). Rather, the incidence of unemployment itself renders people less attractive to prospective employers. In addition, through diverse psychological mechanisms, the experience of unemployment negatively affects the person's further success in job

1 Acknowledgement: This study was funded by the Swiss State Secretariat for Education, Research and Innovation SERI (grant no. 15.0089) as part of the Horizon 2020 project 'Negotiating early job insecurity and labour market exclusion in Europe - NEGOTIATE'. 
searches (Brandt and Hank, 2014: 728). This diminishes the competitiveness and future employment prospects of the (formerly) unemployed. Such lasting negative effects of unemployment on future employment outcomes have become widely known in the literature as scarring.

In these ways, the state of the economy at the time of labour market entry may affect the future careers of young people (Kahn, 2010). Bad luck concerning the timing of labour market entry may translate into persistent disadvantages. In addition to a higher risk of successive unemployment, individuals who graduate in a bad economy may have difficulty gaining access to high-quality jobs with good career prospects after exposure to unemployment. The person may experience lower career advancement, weaker promotion prospects, lower wage growth and less stable labour market integration through his or her engagement in marginal and insecure jobs. Overall, the result is a scarred career.

The initial aim of this study was to measure and explore the dynamics of long-term scarring from an internationally comparative perspective based on a large number of European countries. However, because of data restrictions that were unforeseeable at the beginning of our research we had to reduce our sample to a rather small number of countries. Nonetheless, the five remaining countries - the United Kingdom, Germany, Switzerland, Spain and Finland - serve as interesting comparative cases because they differ remarkably in their institutional and economic dimensions. Such dimensions include the vocational orientation of their education systems, the strictness of employment protection legislation (EPL), the general level of youth unemployment and the active labour market policies (ALMP) in place to support the job-search success of jobless young people. We expect these dimensions to relate to nationally distinct patterns in scarring effects, but because of the small number of countries in our analysis, it is not possible to disentangle the roles of the different institutional factors. This contribution therefore primarily aims at advancing the conceptualization and measurement of long-term unemployment scarring in different institutional and economic contexts. Our focus is on the impact of aggregate youth unemployment in the year of graduation on the career advancement of uppersecondary school-leavers in the first 12 years after graduation. We focus on upper-secondary school graduates - disregarding both upper-secondary dropouts and tertiary graduates - because the persistence of scarring effects depends on education level (the effects for college graduates are more persistent but smaller; Cockx, 2016) and also for reasons of data availability and space limitation. Helbling et al. (2017) have analysed outcomes for tertiary graduates in the five countries studied in this contribution.

More specifically, we (1) investigate whether graduating in times of high aggregate youth unemployment scars the careers of school-leaver 
cohorts; as indicators of such scarred careers, we refer to increased future unemployment and a higher share of fixed-term and involuntary part-time work over a long period of time. To the extent that we find such scarring, we (2) ask whether differences in such effects across countries can be related to the institutional settings of the five European countries under investigation.

This chapter contributes to previous research on unemployment scarring in multiple ways. First, it tackles the theoretical deficit concerning contextual factors that may explain differential patterns and persistency in scarring across institutional settings. In this regard we consider diverse institutional and economic dimensions - such as education systems, EPL, youth labour market policies and the level of youth unemployment - as potential mitigating factors. Second, the chapter offers an internationally comparative analysis of long-term unemployment scarring in the form of successive unemployment and forms of unstable and insecure employment. Third, we exploit exogenous variations in the entry conditions of successive cohorts of school-leavers, which is an under-rated methodological approach that allows us to circumvent the usual endogeneity problems in assessing scarring effects.

\section{THEORETICAL EXPLANATIONS OF UNEMPLOYMENT SCARRING}

Diverse demand- and supply-side mechanisms underlie scarring effects. To summarize briefly, employers' recruitment practices can discriminate against the formerly unemployed such that those who have experienced some unemployment face difficulties and relative disadvantages in future hiring. Extrapolating from signalling theory (Spence, 1973) and statistical discrimination theory (Aigner and Cain, 1977), one would expect employers to be more reluctant to hire individuals with gaps in their work history. Employers may view gaps as signalling that an applicant possesses less ability or is less productive, and they may not solely rely on such applicants' educational qualifications as indicators of their future on-the-job performance. In addition, periods of economic inactivity are likely to hinder the accumulation of job-specific human capital, while previously accumulated human capital may depreciate (Pissarides, 1992). This means that in such situations, (formerly) unemployed persons are in comparatively weaker positions when competing for jobs. Young workers who have experienced long or frequent spells of unemployment are at a disadvantage in the competition for jobs and may receive only 'riskdiscounted' (lower) returns and jobs of lower quality. 
Finally, yet importantly, unemployed people may lower their initial expectations regarding the subsequent quality of their employment and their expected returns (Mortensen, 1986). They may become discouraged (Ayllón, 2013) and to some extent habituated (Clark et al., 2001) to their situation of a bleak employment career. Previous research indicates that the experience of unemployment tends to diminish psychological wellbeing and self-esteem (Goldsmith et al., 1996). Altogether, this gives us reason to expect an altered job-application behaviour in the (formerly) unemployed. This job-application behaviour then becomes manifest in subsequent weaker chances of a successful and stable (re)integration into high-quality jobs.

Such demand- and supply-side mechanisms have proven to be difficult to disentangle in their separate effects. Furthermore, wider institutional contexts are likely to influence these determinants of unemployment scarring and may mitigate the 'costs' of unemployment for subsequent careers, which may result in international differences in the patterns and persistence of scarring. Since research on scarring has so far mainly consisted in national studies on unemployment and wage development, it has not provided a sufficient basis to formulate precise hypotheses about differences in scarring across more diverse employment outcomes, countries and institutional settings. Because of the complexity of investigating institutional effects, the hypotheses that previous studies have advanced have engendered controversy. Against this backdrop, Section 3 below briefly introduces some hypotheses on international differences and the moderating role of institutional settings at the national level.

\section{THE IMPACT OF INSTITUTIONAL AND NATIONAL SETTINGS}

\subsection{Institutional and National Contexts of Unemployment Scarring}

With respect to differences in economic contexts and institutionally embedded pathways for young people from school to work, we consider several assumptions.

First, in countries with nationally standardized initial vocational education and training (IVET) and where hiring strongly relies on IVET credentials as signalling valuable job-specific performance (Breen, 2005; Van der Velden et al., 2001), post-unemployment job matches are likely of a higher quality than in countries without IVET (Dieckhoff, 2011: 237). We assume that in countries with well-established IVET systems, where tight links exist between occupation-specific credentials and prospective 
occupations, scarring will be less profound than in countries without such systems (Hypothesis 1).

Second, we expect weak EPL to allow labour market outsiders such as entrants and the unemployed to (re-)enter the labour market more easily because the dismissal costs are low and work contracts can be easily terminated (Van der Velden et al., 2001). Employers may invest less in screening job applicants' prior work histories and they may be less suspicious towards the unemployed if they can easily dismiss workers. By contrast, strict EPL may intensify unemployment scarring and prolong unemployment, which in turn will exacerbate the loss of human capital and increase unemployment stigma (Breen, 2005; De Lange et al., 2014; Gangl, 2006). Following this line of reasoning, we expect comparatively lower and less persistent scarring in countries with weak employment protection of the permanent workforce than in countries with stricter employment protection (Hypothesis 2.1).

In addition, we assume that not only is re-entry into the labour market more difficult for the unemployed in economies with strict EPL but also that access to permanent and secure jobs is more limited to labour market insiders (De Lange et al., 2014; Dieckhoff, 2011: 236-7; Van der Velden et al., 2001). We therefore expect that the formerly unemployed will be more likely to end up in marginal forms of employment and less secure temporary positions in country contexts with stricter EPL (Hypothesis 2.2).

Third, some researchers have argued that unemployment may be less of a negative signal in countries with high unemployment as opposed to countries with low unemployment (Biewen and Steffes, 2010; Lupi and Ordine, 2002; also see Parsanoglou et al., Chapter 5 this volume). In countries where unemployment is widespread, recruiters may view gaps in job applicants' work histories as resulting from bad luck and structural problems of job shortages and not as indicating negatively connoted individual characteristics. Consequently, we assume that the risk of scarring is greater in countries with lower unemployment rates than in countries with higher unemployment rates (Hypothesis 3).

Fourth, aspects of unemployment benefit systems and, in particular, their generosity in terms of level and duration of benefits may play a role in determining the labour market (re)integration of the unemployed (Brandt and Hank, 2014; Gangl, 2004, 2006). Some scholars have argued, however, that contributory unemployment insurance systems, as they are organized across European countries (Hora et al., 2016), may be less important for supporting young people's job searches and (re)integration success (Kawaguchi and Murao, 2014) because young people with no or little work experience often do not qualify for substantial benefits. We therefore do not expect this institutional dimension to play a significant role in the European context. 
Moreover, several countries have means-tested social assistance and ALMPs that specifically target young people with, for example, job training, upskilling, job-search support and job subsidies (Hora et al., 2016). These measures may assist young people without work in gaining a foothold on the labour market (Kawaguchi and Murao, 2014). Such programmes may also help prevent or counteract young people's loss of human capital, job-search motivation and efforts. The programmes may also reduce employers' anticipated (re)integration costs and hence buffer unemployment scars (Brandt and Hank, 2014; Dieckhoff, 2011: 236; Van der Velden et al., 2001).

But if ALMPs push young people into the job market regardless of job quality - a trend observed in several advanced economies (Bonoli, 2012) they are unlikely to lead to sustainably establishing young people in the labour market. On the contrary, they may even foster scarred careers for unemployed youths. We expect that in countries with ALMPs that concentrate on supporting young people in their job-search strategies and in upskilling (an enabling policy approach; see Sirovátka et al., 2017) there will be less risk of unemployment scarring than in countries where ALMPs primarily aim to push young people into the labour market (a work-first approach) (Hypothesis 4). But there may also be countries where the advancement of young people is mainly a family responsibility and the role for them of ALMPs and social assistance is negligible.

\subsection{Description of Countries: Institutional and Contextual Dimensions}

In this section we briefly describe differences in the relevant institutional characteristics of the five European country cases available in our empirical analysis: Germany, Switzerland, the United Kingdom, Spain and Finland. These five cases encompass a considerable degree of variation regarding the relevant institutional characteristics. Given the small number of countries, it goes without saying that our empirical analysis will be of an exploratory rather than an explanatory, hypotheses-testing nature since we are not able to disentangle the outlined moderating effects of institutional characteristics on the level of scarring. Our empirical analysis aims instead to qualify some of the hypotheses.

\section{Dimension 1: Vocational orientation of the education system}

The United Kingdom has a comprehensive education system, privileging general education at the upper-secondary level (see OECD, 2011: 305), with only a small and decreasing share of students engaged in IVET. Spain has levels of participation in IVET close to the EU/OECD average, while those in Finland exceed the EU/OECD average. In these two 
countries IVET is, however, mainly school based, so it involves the risk of skills mismatch with respect to labour market demands. Participation in work-based apprenticeships or training is very limited (Cedefop, 2013; for Finland, see Duell et al., 2009; OECD, 2011: 305). In contrast, Germany and Switzerland have well-established dual-track IVET systems in which employers are highly involved in determining the training content, and vocational training programmes are nationally standardized. Tight links exist between vocational programmes and the occupationally segmented labour markets (Sacchi et al., 2016). The occupation-specific IVET diplomas qualify the young for skilled employment, providing them with institutionalized pathways to work.

For these reasons, cohorts with upper-secondary education in Switzerland and Germany, which are mainly comprised of company-trained youth, have favourable employment prospects. In contrast, in countries that privilege general education at the upper-secondary level (such as the United Kingdom and Spain; OECD, 2011: 305) and workers with a tertiary education, graduates from vocational education, who are mostly trained at vocational schools, may form a group of less educated entrants with less favourable employment prospects. Following Hypothesis 1, we expect that the vocational diplomas that young people with upper-secondary education receive in countries such as Switzerland and Germany will better protect them from scarring than the vocational diplomas that young people receive in Spain, Finland and the United Kingdom.

\section{Dimension 2: Employment protection legislation (EPL)}

EPL concerns matters such as notice and severance pay and dismissal of employees. EPL has been rather liberal in the United Kingdom and Switzerland (especially for young workers), whereas in Germany, Spain and Finland the protection of the permanent workforce has been stricter and more highly regulated since the 1990s (Hora et al., 2016). In contrast to those employed on permanent contracts, young workers in Spain on fixed-term contracts have weaker employment protection (Cockx, 2016). Following Hypothesis 2, we expect young people to experience less severe scars and to be less likely to end up in marginal and less secure forms of employment in countries with liberal employment protection - such as Switzerland and the United Kingdom (because [re-]entry may be easier if they happen to become unemployed) - than in countries with stricter employment protection.

\section{Dimension 3: Level of (youth) unemployment}

As shown in Figure 4.1, during the period of labour market entries investigated in this study (1991-2012), Switzerland and Germany had relatively 


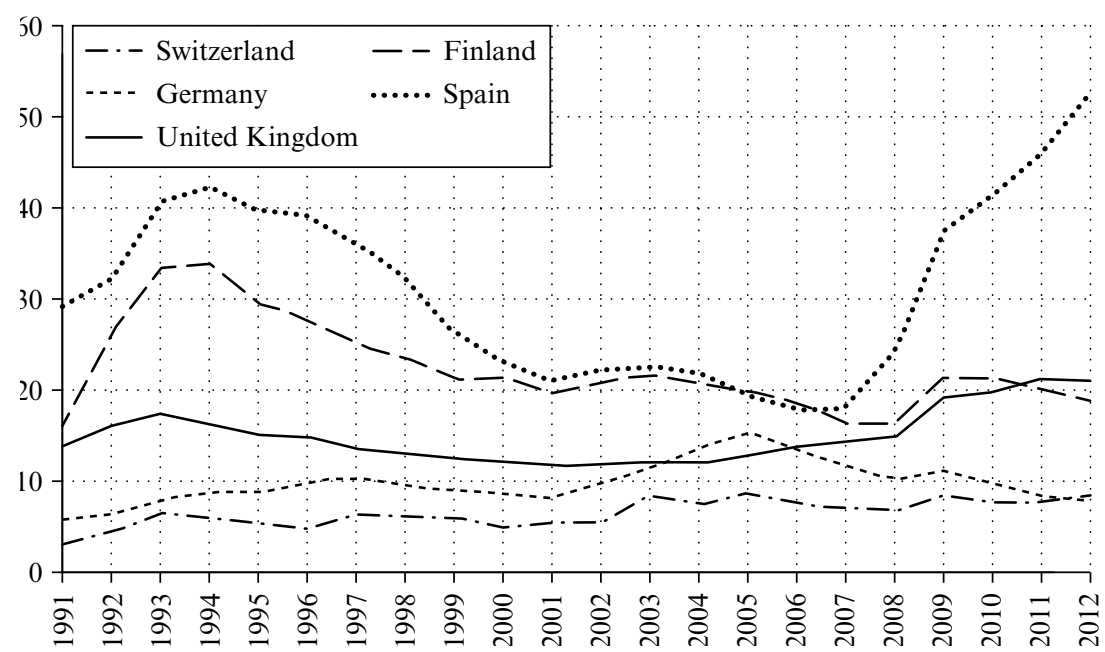

Sources: Eurostat (DE, ES, FI, UK), World Bank (CH).

Figure 4.1 Youth unemployment (\%), ages 15-24, by country and year (1991-2012)

low shares of people in the age group 15-24 who were without work but available for and seeking employment (according to Eurostat and the World Bank data series on youth unemployment). Spain topped the ranking of the selected countries with very high youth unemployment in the mid-1990s and - because of the Great Recession - late 2000s. Finland had high youth unemployment figures in the 1990s too, which dropped to moderate rates in the 2000s. Still, we see the Finnish situation as marked by high youth unemployment again by the mid-2000s. Furthermore, Duell et al. (2009) have noted that Finland has continued to have a relatively high share of temporary contracts amongst young people, in particular for involuntary temporary work. Finally, the United Kingdom is characterized by moderate youth unemployment figures over the two decades compared to the other countries.

Hence, if we follow Hypothesis 3, which states that unemployment gaps in work histories represent a less negative signal if a large share of young people have such gaps, then we might expect early career unemployment to be comparatively less stigmatizing in Spain and Finland than in the United Kingdom and especially less so than in Germany and Switzerland. But this expectation contradicts Hypothesis 1 on the mitigating effects of IVET systems. Since youth unemployment amongst skilled workers 
Table 4.1 Postulated institutional moderators of scarring effects amongst upper-secondary graduates in 1990s and 2000s, by country

\begin{tabular}{llll}
\hline & \multicolumn{2}{l}{ Dimensions impacting on scarring } \\
\cline { 2 - 4 } Country & $\begin{array}{l}\text { Well-established } \\
\text { IVET }\end{array}$ & Liberal EPL & $\begin{array}{l}\text { Youth } \\
\text { unemployment level }\end{array}$ \\
\hline Germany (DE) & Yes & No & Low \\
Switzerland (CH) & Yes & Yes & Low \\
Finland (FI) & No & No & High \\
Spain (ES) & No & No & High \\
United Kingdom (UK) & No & Yes & Moderate \\
\hline
\end{tabular}

Source: Author's interpretation.

is low in countries where (company-based) IVET has an important role, unemployment spells (according to Hypothesis 3 ) may be more negatively evaluated by employers as indicating a lack of 'soft skills' or an inability to perform well in work, devaluing the signalling power of their vocational credentials (Shi et al., 2018). Such complexity surrounding the differential mechanisms of scarring in different contexts obviously hampers the formulation of clear and simple hypotheses. Table 4.1 provides an overview of the role of the country-specific characteristics discussed so far.

\section{Dimension 4: Active labour market policies targeted at youth}

According to a comparative analysis of active labour market policy (ALMP) measures targeted at youth during the 2010s, Germany and Switzerland have continued to show stronger overall levels of activation measures compared to the weaker forms found in the United Kingdom and especially in Spain (Hora et al., 2016). Accordingly, youth policy measures for Germany and Switzerland have followed an enabling approach (Dingeldey et al., 2017) that targets youth who lack qualifications from IVET. In this group we may also include Finland, which has implemented a variety of initiatives aimed at activating jobseekers (Julkunen and Öhman, 2005). By contrast, Spain and the United Kingdom followed a work-first approach, though Switzerland also applies this approach to skilled young workers (e.g., IVET graduates; see Kilchmann et al., 2016).

Most of the countries under investigation introduced youth ALMP measures during the 1990s or early 2010s, which falls within the time period of this study's analysis. Moreover, ALMP measures have been governed and implemented on regional levels, making it difficult to classify the five analysed countries according to the level and quality of their 
youth-oriented ALMPs. However, a comparison of public expenditure on ALMPs as a share of GDP relative to expenditure on passive measures over the past decades confirms that ALMPs have played a particularly marginal role in Spain, where they have only recently become a more relevant strategy for integrating young people (see Ayllón and FerreiraBatista, 2016, and the relevant OECD data). Thus, on the one hand, Spain seems to represent a case where ALMPs have been weakly implemented (and/or used by youth) throughout the period of labour market entries observed in this study, which to some degree stands in contrast to the other countries investigated. On the other hand, we are limited in comparing Spain with the other four countries since we do not have precise information about the respective roles of work-first versus enabling approaches from the 1990s onwards in the remaining countries.

\section{METHODOLOGICAL CHALLENGES IN THE ANALYSIS OF SCARRING EFFECTS}

Empirical work on scarring effects is usually concerned with whether or not individual unemployment episodes early in a person's career have an adverse impact on future labour market outcomes. The focus is thus often on the micro level (Vandenberghe, 2010: 3-4), where - given the problem of endogeneity - a major challenge lies in robustly identifying causal effects of individual unemployment exposure on future employment outcomes. It is difficult to separate individual characteristics associated with a higher risk of unemployment in early career and worse future employment prospects from scarring, and this difficulty may bias the results. Methods that allow for a robust identification of scarring effects at the individual level depend on high-quality (longitudinal) micro data providing information on a wealth of individual characteristics, which hardly exists at an internationally comparative level for investigating long-term scarring effects.

A promising approach to investigating long-term scarring effects from an internationally comparative perspective is to conduct comparative regression analysis on a macro level, where whole cohorts of labour market entrants rather than individuals are the units of analysis. Adopting a macro perspective by comparing aggregated school-leaver cohorts entering the labour market at different points of the business cycle is promising since it exploits exogenous variation in macroeconomic conditions. This allows for a more direct and robust identification of how employment insecurity on labour market entry causally affects the future careers of youth cohorts (Vandenberghe, 2010). This approach thus comes with 
fewer demands concerning the amount of comparable data and the modelling requirements, making it possible to analyse long-term scarring. It offers a feasible way to robustly estimate long-term scarring effects from an internationally comparative perspective (for a rare application of this analytical strategy, see De Vreyer et al., 2000).

\section{DATA}

Our analyses of the five country cases ${ }^{2}$ are based on a pseudo panel that we created using a time series of cross-sectional data sets over the observation window of 2001-13 from the Eurostat Labour Force Survey (EU-LFS), release 2014 (see EU-LFS, 2016). We established the pseudo panel for each country by aggregating the employment outcomes of individuals who belong to the same school-leaver cohort in each survey year over the period of 2001-13. We defined school-leaver cohorts as including all individuals who graduated from upper-secondary education in the same year based on a survey question asking respondents to indicate the year when they successfully completed their highest level of education. We observed career evolvement over a (maximal) span of 12 years since graduation (provided this span fell within the period 2001-13). We therefore had to base our analysis on unbalanced panel data because we could not observe employment outcomes for each cohort for all years since their graduation.

Overall, we used three different measurements of aggregate employment outcomes for 22 school-leaver cohorts: cohort unemployment rate, cohort fixed-term rate and cohort rate of people in involuntary part-time employment. These measurements cover at least some of the first 12 years after graduation in 1991 or later ( $n=153$ aggregated cohort-year observations for each country).

We drew on secondary data (see Figure 4.1) to measure aggregate youth unemployment at the time of graduation. These data provide youth unemployment rates for the selected countries for each year since 1991; unemployment is measured according to the International Labour Organization (ILO) definition, which states that people are unemployed if they are economically inactive and have been either officially registered as unemployed or are actively in search of and available to start a job (ILO,

2 We had initially hoped for a larger sample of countries with more institutional variation, but because of various data-quality issues with the available EU-LFS data, several interesting countries had to be eliminated from our analysis. For instance, the Norwegian EU-LFS data lacked the HATYEAR variable, specifying the year when the highest level of education was successfully completed. 
1982). We based all dependent variables on EU-LFS micro data, which we aggregated to obtain measures on the cohort level:

Unemployment after $x$ years in the labour market is similarly measured according to the ILO definition.

The cohort unemployment rate is the percentage of the total active labour force (which includes the employed and unemployed) in a respective cohort or survey year that is unemployed.

Accordingly, the cohort fixed-term rate is the share of the total amount of people in dependent employment (which includes fixed-term or permanent employment) in a cohort or survey year that has fixed-term work.

The cohort rate of people in involuntary part-time employment is the share of the total amount of people in dependent employment in the same cohort or survey year (which includes involuntary and voluntary part-time as well as full-time employment) who report that they are involuntarily working part time.

\section{ANALYSES}

We made use of weighted least squares linear regression analysis. Since we based the analyses on aggregate data, the number of observations underlying the calculation of aggregate cohort employment outcomes was entered as a weight (see Stock and Watson, 2012: 725-30). We set up the linear regression analyses as follows:

$$
\begin{aligned}
& U_{c t}=\alpha+\beta_{1}\left[u \_ \text {entry } y_{c}\right]+\beta_{2}\left[u \_ \text {entry }\right] \times\left[T(\text { years })_{c t}\right]+\beta_{3}\left[\mathrm{~T}(\text { years })_{c t}\right]+ \\
& \beta_{3} U_{t}+Z_{c} \gamma+\varepsilon_{\mathrm{ct}},
\end{aligned}
$$

where $U_{c t}$ is a vector capturing unemployment rates of cohort $c$ in year $t$, and $\left[u \_e n t r y_{c}\right]$ includes aggregate youth unemployment that the schoolleaver cohorts faced in the year of graduation. The vector T(years) captures the years since graduation. Because cohort unemployment does not linearly decline with the years since graduation, we used fractional polynominals (see Royston and Altman, 1994) in order to find best-fitting transformations to model the relationship between each of the three employment outcomes and the years since graduation for each country.

To allow the effect of initial conditions (aggregate youth unemployment at graduation) to fade or increase over time, we included an interaction $\left.\left.\left(\left[u \_ \text {entry }\right]_{c}\right] \times[\text { T(years })_{c t}\right]\right)$ between the years since graduation and the aggregate youth unemployment at graduation. The vector $U_{t}$ includes aggregate yearly unemployment for the whole working-age population (15-64) in each survey year and serves as a control for further shocks in 
the labour market over the investigation period 2001-13. Our analysis controls for particular effects of the Great Recession in 2008-09 on cohort unemployment (as well as on cohort engagement in fixed-term and involuntary part-time employment) in the respective years. $Z_{c}$ is a set of cohort-specific control variables, which include the male share of the cohort, the mean age and the standard deviation of the age of the cohort as well as a four-year band of cohort dummies to control for cohort effects (De Vreyer et al., 2000). Helbling et al. (2017) have reported the potential gender differences in scarring effects within educational groups of schoolleavers. We have abstained from presenting those findings in detail here because the gender-separated analyses are often based on small numbers of cases and are not sufficiently robust.

Besides investigating successive cohort unemployment, we analysed the successive engagement in fixed-term and involuntary part-time employment by changing the dependent variable $U_{c t}$ to capture average fixedterm or involuntary part-time employment of cohort $c$ in year $t$. Here, $U_{t}$ includes aggregate yearly fixed-term or involuntary part-time employment to control for yearly fluctuations in the share of these work arrangements in different European labour markets.

We conducted the analyses using Stata (version 14). Standard-error estimates take into account clustering in residuals within cohorts.

\section{RESULTS}

\subsection{Unemployment Scarring}

Table 4.2 presents the results for unemployment scarring for school-leaver cohorts with upper-secondary education (for graphical representations of all findings reported in this section, see Helbling et al., 2017). For Switzerland, there was a rather rapid drop in the effects of aggregate youth unemployment at the time of graduation on the cohorts' subsequent unemployment rates. For both the United Kingdom and Germany, however, bad initial labour market conditions in terms of increased unemployment affected the cohorts with upper-secondary education for much longer. The results for the cohorts with upper-secondary education suggest that unemployment scars were particularly persistent in the United Kingdom and Germany. No such unemployment scarring seemed to be at work in Spain and Finland, the two countries with the highest youth unemployment figures. The fact that short-term scarring was most prevalent in Germany and Switzerland - that is, in the two countries with well-established IVET systems and low youth unemployment rates - reso- 
Table 4.2 Marginal effects (and standard errors) of initial unemployment level on unemployment $x$ years after graduation

\begin{tabular}{|c|c|c|c|c|c|c|c|c|c|}
\hline \multirow{2}{*}{$\begin{array}{l}\text { Years since } \\
\text { graduation }\end{array}$} & \multicolumn{2}{|c|}{ FI } & \multicolumn{2}{|c|}{$\mathrm{CH}$} & \multicolumn{2}{|c|}{$\mathrm{DE}$} & \multicolumn{2}{|c|}{ UK } & ES \\
\hline & M.E. & S.E. & M.E. & S.E. & M.E. & S.E. & M.E. & S.E. & M.E. S.E. \\
\hline 1 & 0.176 & 0.151 & $0.557\left(^{*}\right)$ & 0.284 & $0.480(*)$ & 0.233 & $0.265^{*}$ & 0.074 & 0.1420 .101 \\
\hline 2 & 0.152 & 0.121 & 0.204 & 0.143 & 0.308* & 0.118 & $0.265^{*}$ & 0.074 & 0.1020 .068 \\
\hline 3 & 0.134 & 0.101 & 0.087 & 0.112 & $0.266^{*}$ & 0.099 & $0.265^{*}$ & 0.073 & $\begin{array}{lll}0.078 & 0.053\end{array}$ \\
\hline 4 & 0.119 & 0.086 & 0.028 & 0.104 & $0.248 *$ & 0.094 & $0.265^{*}$ & 0.072 & 0.0610 .047 \\
\hline 5 & 0.106 & 0.077 & -0.007 & 0.103 & $0.238^{*}$ & 0.092 & $0.265^{*}$ & 0.071 & $0.048 \quad 0.046$ \\
\hline 6 & 0.093 & 0.073 & -0.031 & 0.103 & $0.232^{*}$ & 0.091 & $0.264 *$ & 0.071 & 0.0370 .048 \\
\hline 7 & 0.082 & 0.073 & -0.047 & 0.105 & $0.229 *$ & 0.090 & $0.263^{*}$ & 0.076 & 0.0280 .052 \\
\hline 8 & 0.072 & 0.076 & -0.060 & 0.106 & $0.226^{*}$ & 0.090 & $0.262 *$ & 0.088 & $0.020 \quad 0.056$ \\
\hline 9 & 0.062 & 0.082 & -0.070 & 0.107 & $0.224 *$ & 0.090 & $0.261^{*}$ & 0.109 & 0.0140 .060 \\
\hline 10 & 0.053 & 0.089 & -0.078 & 0.108 & $0.223^{*}$ & 0.090 & $0.260(*)$ & 0.141 & 0.0070 .064 \\
\hline 11 & 0.044 & 0.097 & -0.084 & 0.109 & $0.222^{*}$ & 0.090 & 0.258 & 0.184 & $\begin{array}{lll}0.002 & 0.068\end{array}$ \\
\hline 12 & 0.036 & 0.106 & -0.089 & 0.110 & $0.221 *$ & 0.090 & 0.256 & 0.239 & $\begin{array}{ll}-0.003 & 0.072\end{array}$ \\
\hline
\end{tabular}

Notes: $\quad * \mathrm{p} \leq 0.05 ;(*) \mathrm{p} \leq 0.1$.

Source: EU-LFS data, author's calculations.

nates both with Hypothesis 3 and with the findings of an in-depth analysis of the NEGOTIATE recruiter data for Switzerland (Shi et al., 2018). The latter has shown that employers assessed former unemployment spells of job applicants with upper-secondary education critically when they hired in Switzerland, where youth unemployment was relatively low. Our hypotheses do not explain, however, why medium- and long-term scarring effects were absent in Switzerland whereas they persisted in Germany and the United Kingdom.

\subsection{Fixed-Term Work}

With regard to the effects that graduating at a time of higher aggregate youth unemployment had on subsequent engagement in fixed-term work for cohorts with upper-secondary education (see Table 4.3), we obtained the following results: For Germany, higher youth unemployment on labour market entry increased the cohort-specific risks of working in fixed-term jobs in the first two years. From eight years after labour market entry onwards, a reversed effect appeared, indicating an increased share of permanent positions for cohorts with harsh entry conditions. One might argue that, because unemployment in Germany had relatively strong scarring effects, IVET graduates were more likely to switch to temporary 
Table 4.3 Marginal effects (and standard errors) of initial unemployment level on fixed-term work $x$ years after graduation

\begin{tabular}{|c|c|c|c|c|c|c|c|c|c|c|}
\hline \multirow{2}{*}{$\begin{array}{l}\text { Years since } \\
\text { graduation }\end{array}$} & \multicolumn{2}{|c|}{ FI } & \multicolumn{2}{|c|}{$\mathrm{CH}$} & \multicolumn{2}{|c|}{$\mathrm{DE}$} & \multicolumn{2}{|c|}{ UK } & \multicolumn{2}{|c|}{ ES } \\
\hline & M.E. & S.E. & M.E. & S.E. & M.E. & S.E. & M.E. & S.E. & M.E. & S.E. \\
\hline 1 & 0.330 & 0.329 & 0.001 & 0.761 & $0.679 *$ & 0.278 & 0.152 & 0.128 & 0.024 & 0.158 \\
\hline 2 & 0.271 & 0.268 & -0.062 & 0.528 & $0.470 *$ & 0.222 & 0.129 & 0.109 & 0.028 & 0.129 \\
\hline 3 & 0.226 & 0.225 & -0.098 & 0.397 & 0.310 & 0.183 & 0.111 & 0.097 & 0.031 & 0.108 \\
\hline 4 & 0.188 & 0.192 & -0.124 & 0.309 & 0.175 & 0.153 & 0.097 & 0.090 & 0.034 & 0.094 \\
\hline 5 & 0.155 & 0.167 & -0.144 & 0.247 & 0.056 & 0.133 & 0.084 & 0.086 & 0.036 & 0.084 \\
\hline 6 & 0.125 & 0.151 & -0.161 & 0.206 & -0.051 & 0.121 & 0.072 & 0.085 & 0.038 & 0.078 \\
\hline 7 & 0.097 & 0.141 & -0.175 & 0.180 & -0.150 & 0.117 & 0.061 & 0.086 & 0.040 & 0.075 \\
\hline 8 & 0.071 & 0.139 & -0.187 & 0.170 & $-0.242(*)$ & 0.120 & 0.051 & 0.089 & 0.042 & 0.077 \\
\hline 9 & 0.046 & 0.143 & -0.197 & 0.171 & $-0.328^{*}$ & 0.128 & 0.041 & 0.093 & 0.044 & 0.080 \\
\hline 10 & 0.023 & 0.152 & -0.207 & 0.180 & $-0.410^{*}$ & 0.141 & 0.032 & 0.098 & 0.045 & 0.086 \\
\hline 11 & 0.002 & 0.163 & -0.216 & 0.193 & $-0.488^{*}$ & 0.155 & 0.024 & 0.103 & 0.047 & 0.093 \\
\hline 12 & -0.019 & 0.178 & -0.223 & 0.210 & $-0.562^{*}$ & 0.171 & 0.016 & 0.109 & 0.048 & 0.100 \\
\hline
\end{tabular}

Notes: $* \mathrm{p} \leq 0.05 ;(*) \mathrm{p} \leq 0.1$.

Source: EU-LFS data, author's calculations.

or other marginal positions, which may have been in their favour in the medium and long term (Gebel, 2013). Germany's enabling approach to ALMPs may have added to this trend, resulting in a long-term stable labour market integration of young workers who graduated at a bad time. In other countries higher aggregate youth unemployment did not seem to relate significantly to increased participation in fixed-term employment amongst cohorts with upper-secondary education. Hence, the careers of cohorts with upper-secondary education graduating at a bad time did not seem to be marked by generally higher engagement in fixed-term work.

\subsection{Involuntary Part-Time Work}

Table 4.4 focuses on the degree of involuntary engagement in part-time work. The results suggest that cohorts with upper-secondary education graduating at a bad time in both Finland and Germany (and to some degree in Spain) - that is, the three countries with stricter EPL - were adversely affected by remarkably higher engagement in involuntary parttime employment in the first few years. In both Germany and Spain, effects were significant up to five years after graduation, while for Finland we found significant effects for two years after graduation, which is consistent with the findings of Duell et al. (2009). In those three countries, involuntary 
Table 4.4 Marginal effects (and standard errors) of initial unemployment level on involuntary engagement in part-time work $x$ years after graduation

\begin{tabular}{|c|c|c|c|c|c|c|c|c|c|c|}
\hline \multirow{2}{*}{$\begin{array}{l}\text { Years since } \\
\text { graduation }\end{array}$} & \multicolumn{2}{|c|}{ FI } & \multicolumn{2}{|c|}{$\mathrm{CH}$} & \multicolumn{2}{|c|}{$\mathrm{DE}$} & \multicolumn{2}{|c|}{ UK } & \multicolumn{2}{|l|}{ ES } \\
\hline & M.E. & S.E. & M.E. & S.E. & M.E. & S.E. & M.E. & S.E. & M.E. & S.E. \\
\hline 1 & 0.591 * & 0.238 & -0.041 & 0.182 & $0.705^{*}$ & 0.088 & -0.065 & 0.077 & $0.133^{*}$ & 0.058 \\
\hline 2 & $0.232 *$ & 0.106 & 0.066 & 0.046 & $0.241^{*}$ & 0.028 & 0.029 & 0.038 & $0.123^{*}$ & 0.055 \\
\hline 3 & 0.112 & 0.071 & $\left.0.0866^{*}\right)$ & 0.044 & $0.125^{*}$ & 0.021 & 0.061 & 0.041 & $0.111^{*}$ & 0.051 \\
\hline 4 & 0.052 & 0.059 & $\left.0.0933^{*}\right)$ & 0.048 & $0.076 *$ & 0.022 & 0.076 & 0.046 & $0.096^{*}$ & 0.046 \\
\hline 5 & 0.016 & 0.055 & $\left.0.0977^{*}\right)$ & 0.050 & 0.051 * & 0.023 & $0.086\left(^{*}\right)$ & 0.050 & 0.080 (* & 0.042 \\
\hline 6 & -0.008 & 0.055 & $\left.0.0988^{*}\right)$ & 0.052 & 0.036 & 0.024 & $0.092(*)$ & 0.052 & 0.062 & 0.037 \\
\hline 7 & -0.025 & 0.055 & $\left.0.0999^{*}\right)$ & 0.053 & 0.025 & 0.025 & $\left.0.0966^{*}\right)$ & 0.054 & 0.042 & 0.033 \\
\hline 8 & -0.038 & 0.056 & $0.100(*)$ & 0.053 & 0.018 & 0.026 & $0.100(*)$ & 0.056 & 0.021 & 0.031 \\
\hline 9 & -0.048 & 0.057 & $0.101\left(^{*}\right)$ & 0.054 & 0.013 & 0.026 & $0.102\left(^{*}\right)$ & 0.057 & -0.002 & 0.031 \\
\hline 10 & -0.056 & 0.058 & $0.101\left(^{*}\right)$ & 0.054 & 0.009 & 0.026 & $0.105\left(^{*}\right)$ & 0.058 & -0.026 & 0.034 \\
\hline 11 & -0.062 & 0.059 & $\left.0.101{ }^{*}\right)$ & 0.054 & 0.006 & 0.027 & $0.106(*)$ & 0.059 & -0.051 & 0.040 \\
\hline 12 & -0.068 & 0.060 & $0.101\left(^{*}\right)$ & 0.054 & 0.004 & 0.027 & $0.108(*)$ & 0.060 & -0.078 & 0.047 \\
\hline
\end{tabular}

Notes: $* \mathrm{p} \leq 0.05 ;(*) \mathrm{p} \leq 0.1$.

Source: EU-LFS data, author's calculations.

part-time work might have been a strategy used by the formerly unemployed to compensate for lack of access to full-time employment, which was less available to them because of the stronger coverage through EPL in the respective countries. Interestingly, cohorts graduating in both the United Kingdom and Switzerland when aggregate youth unemployment was higher were initially not over-represented in involuntary part-time employment. However, there was an increase in involuntary part-time employment (significant effects at $p<0.1$ ) in later years.

\subsection{Comparative Findings}

Table 4.5 briefly summarizes the findings reported above in a comparative way, where long-term scar refers to scarring effects persisting for at least six years, medium-term scar refers to a scar lasting three to five years and a short-term effect refers to an initial effect of up to two years since graduation.

We may note that we found scarring in employment outcomes such as successive unemployment, fixed-term employment and involuntary part-time work in very diverse institutional contexts and of different durations. But we did not find a clear and easily interpretable pattern in the institutional characteristics that mitigated scarring effects in the five 
Table 4.5 Country overview of estimated scarring effects from graduating during an economic downturn

\begin{tabular}{|c|c|c|c|c|c|c|}
\hline & \multicolumn{3}{|c|}{ Institutional dimensions } & \multicolumn{3}{|l|}{ Scarring effects } \\
\hline & $\begin{array}{l}\text { Dual } \\
\text { IVET }\end{array}$ & $\begin{array}{l}\text { Liberal } \\
\text { EPL }\end{array}$ & YUE & Unemployment & $\begin{array}{l}\text { Fixed-term } \\
\text { work }\end{array}$ & $\begin{array}{l}\text { Involuntary } \\
\text { part-time work }\end{array}$ \\
\hline $\mathrm{DE}$ & Yes & No & Low & long-term & $\begin{array}{l}\text { short-term } \\
\text { scars, long- } \\
\text { term benefits }\end{array}$ & medium-term \\
\hline $\mathrm{CH}$ & Yes & Yes & Low & short-term & - & increasing \\
\hline FI & No & No & High & - & - & short-term \\
\hline ES & No & No & High & - & - & medium-term \\
\hline UK & No & Yes & Moderate & long-term & - & increasing \\
\hline
\end{tabular}

Notes: Long-term effects ( $>=6$ years); medium-term effects ( $3-5$ years); short-term effects ( $<3$ years); - no scarring.

Source: Author's interpretation.

countries analysed. One reason might be that highly educated youth (e.g., college graduates) may have experienced smaller but more persistent penalties from graduating in a recession - especially in rigid labour markets (Cockx, 2016) - than the upper-secondary school cohorts analysed in this contribution. Nonetheless, our findings show some interesting patterns: whereas national unemployment contexts seem to matter more for unemployment scarring, EPL contexts seem more relevant with respect to involuntary part-time work. The institutional effects on fixed-term work as a consequence of graduating during an economic downturn remain less clear in that we only find respective scarring effects in the case of Germany.

Given the limited number of countries we were able to consider in our analysis, the rather complex pattern of institutional characteristics and scarring effects in our data is not much of a surprise. Some of our results are quite sensitive to the inclusion or exclusion of specific school-leaver cohorts, suggesting that one would need a longer observation period to better control for heterogeneity in scarring over time and over entry cohorts. In order to obtain clear-cut conclusions regarding the moderating role of different institutional characteristics, the analysis would need to be extended to a larger number of countries (including non-European countries) representing institutional variations as fully as possible, and also to longer observation spans. Cockx (2016) has found that the evidence from European studies concerning persistent scarring effects from graduating in a recession are generally less clear cut because those countries occupy 
a middle position with respect to labour market rigidity compared to the more flexible North American labour markets or the very rigid Japanese labour market.

\section{CONCLUSIONS}

Summing up, we found evidence that bad luck in the timing of labour market entry scars the long-term future careers of upper-secondary school-leaver cohorts concerning various subsequent employment outcomes across European countries. Graduating at a time of higher aggregate youth unemployment affects subsequent cohort unemployment and leads to over-representation in insecure forms of work such as fixed-term and involuntary part-time employment. Increased unemployment and engagement in marginal forms of work may be thought to further hamper the career advancement of youth cohorts; for example, it might affect their wages (Cockx, 2016), professional development (Van den Berge and Brouwers, 2017) or the skill adequacy of their employment. These aspects are not depicted in this study but deserve more in-depth attention in scarring analyses in future research so as to obtain a more comprehensive understanding of how a short-term scar in one employment domain may relate to longer-term scars in other domains. All in all, our findings suggest that there are substantial scarring effects on various employment outcomes in very diverse institutional settings. This result should be of great interest to policymakers seeking to prevent 'lost generations'.

A clear-cut picture of how institutional characteristics mitigate scarring effects does not emerge from our case study, however. This has an obvious methodological cause and perhaps also less evident fundamental ones. From a methodological point of view, an analysis with a much larger country sample observed over a longer period would be required to disentangle the expected moderating effects of the various potentially important institutional factors. Because of restrictions related to the EU-LFS data, we had to limit our study to five countries observed over a relatively short observation period and, consequently, to a rather exploratory analysis. Another methodological reason why our evidence is not very clear cut might be the fact that European labour markets in general occupy middle positions on an international scale of labour market rigidity.

From a substantive point of view, we have derived some tentative hypotheses from the literature pertaining to the mitigating role of four different institutional or contextual variables. But there potentially are many interacting institutional characteristics that might, in principle, affect scarring. One could, for instance, easily propose additional country-level 
factors with a possible impact on scarring, such as the degree of globalization (see De Lange et al., 2014). An increase in flexible and non-standard work arrangements may shift unemployment scarring towards scarring from engagement in atypical or marginal forms of employment and non-standard careers, which may be evaluated as negative productivity indicators by employers (Pedulla, 2016).

To complicate things further, scarring effects are likely to vary not only across institutional settings but also across different groups of workers (Plum and Ayllón, 2015), such as those with different educational levels or in different gender categories. Gender-separate analyses by Helbling et al. (2017) suggest that the findings presented above may mask gender differences in employment outcomes. For example, analyses conducted that include a gender dimension suggest some long-term unemployment scarring for female upper-secondary school graduates in Germany and in Finland, while for the United Kingdom long-lasting unemployment scarring seems to pertain more to men with upper-secondary school diplomas. For Spain, as well as to some extent for the United Kingdom and Finland, results also suggest some long-term scarring in terms of an over-representation in fixed-term work for cohorts of female upper-secondary school graduates, while increased shares in involuntary part-time employment over the course of the career is more a male phenomenon in Switzerland.

Many factors might potentially explain the observed variation in scarring effects across different institutional settings or worker groups. A sound conceptualization of the institutional framing of scarring effects would require a well-established micro theory of their behavioural foundations, both for employers and for jobseekers or workers. Without such a micro theory, it is difficult to derive concise theoretical expectations for the patterns of aggregate effects from institutional settings or worker groups.

\section{REFERENCES}

Aigner DJ and Cain GG (1977) Statistical theories of discrimination in labor markets. Industrial Labor Relations Review 30(2): 175-87.

Arulampalam WP, Gregg P and Gregory M (2001) Unemployment scarring. Economic Journal 111(475): 577-84.

Ayllón S (2013) Unemployment persistence: Not only stigma but discouragement too. Applied Economics Letters 20(1): 67-71.

Ayllón S and Ferreira-Batista N (2016) Institutional determinants of early job insecurity in nine European countries. National Report Spain for NEGOTIATE Working Paper no. 3.4. https://negotiate-research.eu/files/2015/03/WP-3.4_Spa in_National-report.pdf (accessed 2 June 2018). 
Biewen M and Steffes S (2010) Unemployment persistence: Is there evidence for stigma effects? Economics Letters 106(3): 188-90.

Bonoli G (2012) Active labour market policy and social investment: A changing relationship. In: Morel N, Palier B and Palme J (eds) Towards a Social Investment Welfare State? Ideas, Policies and Challenges. Bristol: Policy Press, pp. 181-204.

Brandt M and Hank K (2014) Scars that will not disappear: Long-term associations between early and later life unemployment under different welfare regimes. Journal of Social Policy 43(4): 727-43.

Breen R (2005) Explaining cross-national variation in youth unemployment: Market and institutional factors. European Sociological Review 21(2): 125-34.

Cedefop (2013) On the way to 2020: Data for vocational education and training policies: Country statistical overviews. Research Paper no. 31. Luxembourg: Publications Office of the European Union.

Clark AE, Georgellis Y and Sanfey P (2001) Scarring: The psychological impact of past unemployment. Economica 68(270): 221-41.

Cockx B (2016) Do youths graduating in a recession incur permanent losses? Penalties may last ten years or more, especially for high-educated youth and in rigid labor markets. IZA World of Labor no. 281. DOI: 10.15185/izawol.281.

De Lange M, Gesthuizen M and Wolbers M (2014) Youth labour market integration across Europe. European Societies 16(2): 194-212.

De Vreyer P, Layte R, Hussain A and Wolbers M (2000) The permanent effects of labour market entry in times of high unemployment. In: Gallie D and Paugam $\mathrm{SP}$ (eds) Welfare Regimes and the Experience of Unemployment in Europe. Oxford, UK: Oxford University Press, pp. 134-52.

Dieckhoff M (2011) The effect of unemployment on subsequent job quality in Europe: A comparative study of four countries. Acta Sociologica 54(3): 233-49.

Dingeldey I, Assmann ML and Steinberg L (2017) Strategies to improve labour market integration of young people: Comparing policy coordination in nine European Countries. NEGOTIATE Working Paper no. 8.2. https://negotiate-research.eu/ files/2015/04/NEGOTIATE_WP_8.2-_Strategies-to-improve-labour-market-int egration-of-young-people.pdf (accessed 29 April 2018).

Duell N, Grubb D and Singh S (2009) Activation policies in Finland. OECD Social, Employment and Migration Working Paper no. 98. Paris: OECD. DOI: 10.1787/220568650308.

EU-LFS, Eurostat Labour Force Survey (2016) Employment and unemployment (LFS) - Overview. http://ec.europa.eu/eurostat/web/lfs/overview (accessed 18 May 2016).

Gangl M (2004) Welfare states and the scar effects of unemployment: A comparative analysis of the United States and West Germany. American Journal of Sociology 109(6): 1319-64.

Gangl M (2006) Scar effects of unemployment: An assessment of institutional complementarities. American Sociological Review 71(6): 986-1013.

Gebel M (2013) Is a temporary job better than unemployment? A cross-country comparison based on British, German, and Swiss panel data. SOEPpapers on Multidisciplinary Panel Data Research 543. Berlin: German Socio-Economic Panel Study, DIW Berlin.

Goldsmith AH, Veum JR and Darity W (1996) The impact of labor force history on self-esteem and its component parts, anxiety, alienation and depression. Journal of Economic Psychology 17(2): 183-220. 
Helbling LA, Sacchi S and Imdorf C (2017) Understanding cross-country variation in the long-term consequences of graduating at a bad time: A comparison of five European countries. NEGOTIATE Working Paper no. 6.3. https://negotiate-resea rch.eu/files/2015/04/NEGOTIATE_working_paper_6.3.pdf (accessed 29 April 2018).

Hora O, Horáková M and Sirovátka T (2016) Institutional determinants of early job insecurity in nine European countries. NEGOTIATE Working Paper no. 3.4. https://negotiate-research.eu/files/2015/04/NEGOTIATE-working-paper-D3.4. pdf (accessed 29 April 2018).

ILO (1982) Resolution concerning statistics of the economically active population, employment, unemployment and underemployment, adopted by the Thirteenth International Conference of Labour Statisticians. Geneva: International Labour Organization. http://www.ilo.org/wcmsp5/groups/public/---dgreports/---stat/docu ments/normativeinstrument/wcms_087481.pdf (accessed 10 June 2018).

Julkunen I and Öhman J (2005) Finland. In: Walther A and Pohl A (eds) Thematic Study on policy measures concerning disadvantaged youth: Final report, Vol. 2 Annexes II-VI. Tübingen: Institute for Regional Innovation and Social Research (IRIS), pp. 53-69.

Kahn LB (2010) The long-term labor market consequences of graduating from college in a bad economy. Labour Economics 17(2): 303-16.

Kawaguchi D and Murao T (2014) Labor-market institutions and long-term effects of youth unemployment. Journal of Money, Credit and Banking 46(S2): 95-116.

Kilchmann V, Kobler C, Shi LP and Imdorf C (2016) Strategies to improve labour market integration of young people: Comparing policy coordination in nine European countries. National Report Switzerland for NEGOTIATE Working Paper no. 8.2. https://negotiate-research.eu/files/2015/03/D8.2_Country_Report_ Switzerland.pdf (accessed 10 June 2018).

Lupi C and Ordine P (2002) Unemployment scarring in high unemployment regions. Economics Bulletin 10(2): 1-8.

Mortensen D (1986) Job search and labor market analysis. In: Ashenfelter O and Layard R (eds) Handbook of Labor Economics, vol. 2. Amsterdam: Elsevier, pp. 849-919.

OECD (2011) Education at a Glance 2011. Paris: OECD.

OECD (2017) Labour Force Statistics 2016. Paris: OECD.

OECD Observer (2010) Lost generation? http://www.oecdobserver.org/news/arch ivestory.php/aid/3257/Lost_generation_.html (accessed 15 June 2016).

Pedulla DS (2016) Penalized or protected? Gender and the consequences of nonstandard or mismatched employment histories. American Sociological Review 81(2): 262-89.

Pissarides CA (1992) Loss of skill during unemployment and the persistence of employment shocks. Quarterly Journal of Economics 107(4): 1371-91.

Plum A and Ayllón S (2015) Heterogeneity in unemployment state dependence. Economics Letters 136: 85-7.

Royston P and Altman DG (1994) Regression using fractional polynomials of continuous covariates: Parsimonious parametric modeling. Journal of the Royal Statistical Society 43(3): 429-67.

Sacchi S, Kriesi I and Buchmann M (2016) Occupational mobility chains and the role of job opportunities for upward, lateral and downward mobility in Switzerland. Research in Social Stratification and Mobility 44: 10-21. 
Shi LP, Imdorf C, Samuel R and Sacchi S (2018). How unemployment scarring affects skilled young workers: Evidence from a factorial survey of Swiss recruiters. Journal of Labour Market Research. 52:7. DOI: 10.1186/s12651-018-0239-7.

Sirovátka T, Hora O and Horáková M (2017) The fight against youth unemployment: Enhancing the chances of success by strengthening linkages between horizontal and vertical policy coordination. NEGOTIATE Working Paper no. 8.4. https:// negotiate-research.eu/files/2018/06/NEGOTIATE_working_paper_8.4.pdf (accessed 20 June 2018).

Spence M (1973) Job market signaling. Quarterly Journal of Economics 87(3): 355-74.

Stock JH and Watson MM (2012) Introduction to Econometrics. 3rd ed. Boston, MA: Pearson.

Vandenberghe V (2010) The long-term effects of recessions on youth: Reviewing the evidence. Louvain: Université catholique de Louvain (UCL), Economics School of Louvain.

Van den Berge W and Brouwers A (2017) A lost generation? The early career effects of graduating during a recession. CPB Discussion Paper no. 356. The Hague: CPB Netherlands Bureau for Economic Policy Analysis.

Van der Velden R, Welters R and Wolbers M (2001) The integration of young people into the labour market within the European Union: The role of institutional settings. Working Paper no. 7E. Maastricht: Research Centre for Education and the Labour Market. 